\title{
Novos rumos para o Drama: August Strindberg e a realização de Rumo a Damasco.
}

\author{
CARLOS AFONSO MONTEIRO RABELO
}

Carlos Rabelo é dramaturgo, tradutor e músico. Faz parte do grupo de teatro VerusGladiatores, de Goiânia, onde teve duas peças inéditas encenadas, "Hora de Fechar" (2012) e "Alfândega" (2013) e desenvolve trabalho de tradução voltado à dramaturgia escandinava, tendo traduzido Henrik Ibsen, Per-Olov Enqvist e August Strindberg para edições e montagens. É licenciado em Artes Cênicas (UFG) e atualmente é mestrando da Faculdade de Letras em Estudos Literários com o projeto "Um estudo metodológico do ensino em dramaturgia: ensaiando para escrever", com orientação do Pr. Dr. Cássio Tavares. 


\section{- RESUMO}

Este artigo comenta a importância de August Strindberg para a dramaturgia do século $\mathrm{XX}$, as principais características de sua obra e o que representa o surgimento de um gênero dramático inédito: a peça-sonho. A partir de uma análise de "Rumo a Damasco", vemos como as intenções do dramaturgo se expressam no enredo da peça, seus símbolos e alegorias, e das referências ao teatro medieval. E por fim, como se deu a estreia de "Rumo a Damasco", como foi a recepção da crítica e suas montagens mais importantes.

\section{- PALAVRAS-CHAVE}

August Strindberg, Rumo a Damasco, Teatro, Dramaturgia.

\section{- ABSTRACT}

This article comments the importance of August Strindberg for the drama of the twentieth century, the main features of his work and the emergence of an unprecedented dramatic genre: the dreamplay. From an analysis of "To Damascus", we can see the playwright's intentions expressing themselves in the play's plot, its symbols and allegories, and references to medieval theater. And finally, how was the premiere of To Damascus, the critical reception and important productions.

\section{- KEYWORDS}

August Strindberg, To Damaskus, Theater, Playwriting.

Neste artigo vamos apresentar algumas considerações sobre a peça de teatro "Rumo a Damasco", de August Strindberg (1849-1912) e sobre este autor. Esta obra tem importância central para a compreensão do teatro que se faria no decorrer do século XX, e também para a trajetória estética deste dramaturgo. Serve tanto para se entender um momento de transição e crise na história do drama, quanto para compreender o tempo em que foi escrita, e as múltiplas contradições que engendraram nossa contemporaneidade.

O Drama e as Artes Cênicas dos séculos XX e XXI foram profundamente impactados pela dramaturgia do escritor sueco August Strindberg (1849-1912). Sua influência se estendeu a quase todos os dramaturgos das gerações seguintes, que se apropriaram de sua "dramaturgia do eu", particularmente os expressionistas como Georg Kaiser (1878-1945), Eugene O’Neill (1888-1953) e nas primeiras peças de Bertolt Brecht (1898-1956). E também dos que desenvolveram os ramos naturalistas e simbolistas de sua obra, representados nas peças de câmara e nas peças-sonho, entre os quais se pode destacar Jean-Paul Sartre (19051980), Albert Camus (1913-1960), Harold Pinter (1930-2008) e Edward Albee (1928). 
É impossível rotular a dramaturgia de Strindberg, cuja versatilidade, fecundidade atravessa e combina diversos movimentos literários. Por este motivo, determinar Strindberg como naturalista, simbolista ou expressionista é uma tarefa fadada ao fracasso. O que se reflete na personalidade paradoxal do autor: um misógino a favor do voto feminino - num período histórico onde essa era uma posição radical -, um homem profundamente espiritual obcecado com os caminhos da ciência moderna e um militante darwinista que se perdeu nos labirintos da alquimia. Talvez, como bom homem de teatro, parte dessa inconsequência fosse jogo de cena, ou, ele lutou em vários fronts na tentativa de triunfar em ao menos um. Em todo caso, sua dramaturgia apontava para o futuro, como bem notou o romancista alemão Thomas Mann:

\begin{abstract}
Como poeta, pensador, profeta, e criador de um novo mundo de sentimentos, Strindberg está tão a nossa frente que mesmo hoje sua obra não aparenta estar nem um pouco ultrapassada. Ele está ao largo e a acima de todas as escolas e movimentos, e assim ele une todos. Um naturalista, tanto quanto um neo-romântico, ele antecipa o expressionismo, fazendo uma geração inteira que trabalhou sob este nome, devedora a ele. Ao mesmo tempo, ele é o primeiro surrealista - o primeiro em todo sentido da palavra (MANN, apud RUGG, 2009, p.6, tradução nossa) ${ }^{1}$.
\end{abstract}

Para compreender o que Mann quis dizer com "surrealista" é necessário se debruçar sobre as peças-sonho que Strindberg passaria a escrever a partir de 1898. Elas serviram de inspiração para inúmeros artistas da cena e da literatura desde o ano de estreia e publicação até nossos dias. E entre elas, "Rumo a Damasco" foi a primeira a ser escrita, sendo assim a precursora da fase mais influente da dramaturgia strindberguiana.

Contudo, muitas de suas peças mais montadas são "dramas familiares" como "Senhorita Júlia" (1888), “A dança da morte" (1900), "Sonata dos espectros" (1907), “O pelicano" (1907) que costumam ter por tema amores destrutivos, casamentos, artistas, vida boêmia e família em crise. Para escrevê-las, usou sua própria vida como modelo, sua patológica dificuldade em se relacionar com as mulheres, criando assim os mais vivos e assustadores retratos da guerra entre os sexos.

\footnotetext{
${ }^{1}$ No original: As poet, thinker, prophet, and originator of new world of feeling, Strindberg is so far advanced that even today [a half-century later] his work does not seem in the least exhausted. Standing outside and above schools and movements, he unites them all. A Naturalist well as a neo-Romantic, he anticipates Expressionism, making the entire generation working under that name indebted to him. At the same time, he is the first Surrealist - the first in every sense (MANN, apud RUUG, 2009, p.6).
} 
Por outro lado, ele criou um gênero novo, peças que desconsideram limites do tempo e do espaço, a peça-sonho, no qual se destacam "O Sonho" (1901) e "Rumo a Damasco" (1898), que vamos analisar com mais profundidade logo em seguida. Este gênero se tornou uma fonte de inspiração para as vanguardas teatrais dos séculos XX e XXI, em especial para os criadores do assim chamado teatro pós-dramático.

Outra característica marcante de Strindberg era a rara coragem com que se autobiografava em luzes nada lisonjeiras, o que à época era tido como falta de decoro surgindo como personalidade central de parte de seus dramas e de sua prosa. Como os grandes atores que não se importam em se expor ao nível mais íntimo, Strindberg levou a exposição própria a limites inauditos. Por isso mesmo, apesar de ter escrito prosa, poesia, jornalismo, história e teoria, foi no teatro onde ele deixou uma marca mais forte.

O estilo dramático de Strindberg é marcado por súbitas oscilações de humor. Registrava em suas peças a própria instabilidade emocional e psíquica, com diálogos ágeis, coloquiais, com muitos pontos de exclamação, e terríveis acusações, ameaças e chantagens, especialmente entre cônjuges. Ao contrário de dramaturgos que constroem gradações emocionais que podem levar muitos atos, os personagens de Strindberg se lançam em precipícios de sofrimento, raiva, alegria, no intervalo de poucas falas. Além do desafio que isso representa para os atores, por um lado seus textos podem apresentar tons melodramáticos, por outro tem a vantagem de raramente aborrecer.

Dentre os temas que abordou, além da destrutiva relação com as mulheres, encontramos outra obsessão em Strindberg: sua espiritualidade, sua busca pelo divino e por Deus. Mesmo após abandonar o ateísmo que marcou o início de sua carreira, sua fé jamais seria totalmente segura. Não tendo esperança nem no afeto das mulheres, nem no amor de Deus, ele criou personagens que desistem da civilização, demonstrando o lado selvagem do ser humano, como o personagem título de "Senhorita Júlia" (OLLÉN, 1984).

Mesmo após a mudança de costumes que se observou no século XX, com o aumento da tolerância e o crescente interesse em discutir questões antes vedadas ao teatro, como a sexualidade, o inconsciente, a irracionalidade, Strindberg permaneceu sendo polêmico, 
maldito e mal compreendido desde sua aparição até os dias atuais. Ele nunca foi um autor verdadeiramente amado, nem em seu país natal, e tampouco no resto do mundo, onde parte de sua literatura aguarda tradução, especialmente sua prosa. Um dos motivos que dificultaram a universalização de sua obra foi o fato dela ter sido escrita em um idioma periférico, o sueco, o qual Strindberg mudou para sempre com sua irreverência e criatividade. Escrevia em um estilo a frente de seu tempo, e, como bom dramaturgo, não se importava em escrever do modo com que as pessoas falam: usava sem medo palavrões, regionalismos e por este motivo, parte de seu brilho se perde nas traduções.

De sua enorme dramaturgia de cerca de sessenta peças, grande parte é esquecível. É um autor desigual que escrevia obsessivamente. No entanto, ao menos nove de suas peças são montadas com frequência mundo afora, e funcionam hoje tão bem, ou melhor, do que quando foram estreadas. São elas: "O Pai", "Senhorita Júlia", "Credores", "A Dança da Morte", "Rumo a Damasco", "Érico XIV" (inédita em português), "A donzela" (inédita em português), "O Sonho", e "Sonata dos Espectros" (MEYER, 1985, p.579).

Resta dizer em defesa do autor que a merecida fama de misógino e louco foi em parte criada por ele mesmo. Suas frequentes mudanças de opinião, seus rompimentos com amigos, sua mania de perseguição, a constante suspeição de doença psiquiátrica, tudo isso serviu de carta-branca para que ele compusesse retratos clinicamente honestos e cruéis da mente humana. E quanto à misoginia, sua sequência de casamentos e separações, os conturbados relacionamentos com mulheres e com o nascente movimento feminista, e suas opiniões cambiantes acerca do mesmo, serviram de estofo para o retrato de mulheres terríveis, fascinantes, e assustadoramente reais que povoam suas peças.

Entre seus inúmeros interesses se encontrava a literatura médica, em especial a psiquiatria. Seu intento era examinar a mente humana através de suas peças, sendo ele mesmo a cobaia. Ele sonhava criar uma obra literária que fosse também um projeto científico (SZALCZER, 2011). Apesar de sabermos hoje que tal vontade não se concretizou, e nem jamais poderia dar certo, este tipo de ideia que oscila entre insanidade e genialidade é a marca característica deste autor. 
A peça "Rumo a Damasco" é a primeira parte de uma trilogia, completada por Till Damaskus II (1898) e Till Damaskus III (1901). Nesta primeira parte da trilogia, que aqui discutimos, é mostrada a estória de O Desconhecido, um alter ego do autor em sua peregrinação espiritual para se afastar de uma crise psíquica - ao molde da que é relatada com rara coragem na novela "Inferno" (1898) - a caminho de uma renovada fé em Deus. Daí a referência à viagem de Saulo. A conversão é evocada no título, mas a peça está longe de ser um drama cristão de final feliz. Antes de fazer um breve resumo da peça, cabe mencionar sua rigorosa estrutura em cinco atos, ao sabor clássico, e a perfeita simetria dos seus nove cenários, o primeiro sendo o último, o segundo o penúltimo, e assim por diante, como "uma cobra que morde o próprio rabo" nas palavras do autor, em uma carta para seu amigo Geijerstam (SZALCZER, 2011, p. 86). A estrutura circular, eterna, além da simbologia religiosa que remete ao divino, é também um sinal de desesperança, de ausência de escapatória, negando assim o crescimento, a descoberta pessoal que é reservada ao herói do drama convencional.

No vértice formado por estes cenários está situado o Asilo - a abadia da Boa Esperança - onde não por acaso a redenção está à espera do protagonista, onde ele é acolhido, tratado, mas mesmo assim parte a caminho de novas provações, ao que o personagem Confessor exclama: “Louco! Louco!". E é justamente o cenário onde o protagonista se sente mais perdido, mais preso aos seus demônios.

A peça começa em uma esquina, uma escolha evidentemente simbólica. A esquina evoca caminhos diversos a se escolher, encruzilhadas, peregrinações e o indivíduo perdido em busca de uma destinação. A rubrica prevê uma igreja gótica, em oposição a um café. De um lado a salvação via Deus, e do outro a vida boêmia dos artistas. Dois polos de influência, de atração, além da agência de correio, onde Desconhecido - um personagem que obviamente contém vários elementos autobiográficos - espera ansiosamente a chegada de uma boa notícia em forma de dinheiro. Significativamente, o café e o correio estão de portas fechadas. Ouve-se uma marcha fúnebre. Durante a peça não saberemos quem morreu. Mas nada é posto no palco sem motivo. O que morreu é a vida que o escritor tivera até então: suas ambições, seu casamento e suas crenças. Então se dá o encontro dos dois personagens centrais do drama: o Desconhecido e a Dama, a quem mais adiante o protagonista chamará 
de Eva, outra referência bíblica, e a que os pais chamarão de Ingeborg, nome sueco de sonoridade burguesa e bem comportada - um equivalente brasileiro seria Conceição ou Guiomar. O encontro dos dois tem algo de constrangedor, desajeitado - como se não soubessem de fato o que querem um do outro. Não é um encontro romântico, é o encontro de dois condenados a uma peregrinação.

Pelos diálogos que se seguem, sabemos que ela é sua admiradora e que eles se conheceram recentemente num evento social. E, também, que o escritor é odiado por defender posições polêmicas, referência aos anos de socialista de Strindberg, e também de sua perambulação pelo mundo - a que ele dramaticamente se refere como "exílio". Strindberg gostava de se declarar um exilado, quando de fato jamais foi expulso da Suécia. Ele a deixou por que era notadamente paranoico, e se via perseguido por críticas ruins, indiferença e credores.

Voltando ao enredo do primeiro ato, a informação mais importante que se desprende da cena inicial é a profunda desilusão, tema central da peça, um desespero que se intensifica a tal ponto, que se transforma em doença mental. Outro ponto importante para a trama que então se apresenta é o juramento que o escritor impõe à Dama: não ler seu último livro. Vemos aí uma provável referência à novela "Inferno", escrita logo antes desta peça e onde se deu um ponto de inversão na vida e na literatura de Strindberg. Em seguida, a Dama o deixa e vai à igreja. Segue então uma cena de humor negro: o Mendigo, personagem excêntrico, latinista, aproxima-se e, pela primeira vez, sentimos o incômodo e o medo do Desconhecido, que desconfia da realidade do Mendigo. Este possui uma cicatriz idêntica ao do protagonista e parece dizer coisas que poderiam sair da mente do Desconhecido. Sendo um autor geralmente identificado com o tom trágico de suas obras, deve-se sempre frisar a verve cômica deste dramaturgo, que possui cenas verdadeiramente engraçadas em "O Sonho" (onde há uma cena paródica com doutos da academia) e até mesmo uma novela de tom popular e cômico, "Gente de Hemsö". Como Shakespeare, ele não se importava em mesclar o cômico e trágico.

Após o encontro com o Mendigo, o protagonista se depara com um grupo de carpinteiros enlutados, que bebem e ridicularizam a memória do falecido anônimo. A marcha fúnebre que soa na cena inicial é ouvida então mais uma vez, como também será no 
decorrer da peça, um leitmotiv macabro que persegue o Desconhecido. Neste encontro com os carpinteiros, há um bom exemplo de como se estabelece a sensação de irrealidade, vivenciada pelo protagonista, e por extensão também para o público. O Desconhecido pergunta aos carpinteiros enlutados por que estão vestidos de marrom. Estes respondem que estão na verdade vestidos de preto. Porém, o público vê o mesmo tom de marrom que o Desconhecido vê. Assim, os espectadores embarcam no mundo de incertezas que o Desconhecido percorre. (RUGG, in ROBINSON, 2009, p.15).

A Dama retorna e tenta convencer o Desconhecido a visitar um médico, que será a primeira de muitas menções a doenças mentais e hospícios. Os dois vão então ver o Médico, o marido da Dama. É um casal separado e que vive então um típico inferno matrimonial strindberguiano. Sob os cuidados do médico, está o Louco, apelidado César, o mesmo apelido que o Desconhecido tinha nos tempos de colégio, uma paródia da derrisão do grande homem, do grande escritor enlouquecido e odiado. O próprio Médico pode ser compreendido como uma versão aburguesada de Strindberg, em voltas com a mediocridade de seu trabalho, um casamento em frangalhos e secretamente sonhando com a vida boêmia dos artistas, representada no escritor que o visita. Após esse estranho encontro, vemos um típico final de primeiro ato: uma partida em rumo impreciso, quando o Desconhecido e a Dama - que abandona de vez o marido - seguem pela estrada.

No começo do segundo ato, o Desconhecido e a Dama passam o constrangimento de não conseguirem hospedar-se num hotel, quando seus documentos são checados. Estão juntos sem serem casados, e mais uma vez terão que ir embora. Cabe lembrar que nessa época a Suécia não era o país liberal que hoje conhecemos, e uma cena como essa tinha um forte teor de provocação. E o autor parece reprovar também a conduta do casal, como que se unisse aos seus detratores. Logo em seguida, após um breve idílio de três dias - de claro subtexto sexual - o protagonista é tomado de inquietação, por saber que a felicidade sempre escapa de suas mãos. E o anúncio do reinício do calvário é uma carta informando que o dinheiro, como sempre, acabou. Em fúria, ele desafia os raios e trovões de Deus, para o terror da Dama. Aqui também se vê uma dose de humor: um escritor falido desafiando a Deus para o escândalo da senhora que o acompanha. Neste momento não vemos um 
sofrimento trágico, o sofrimento de um homem de estatura. É um sofrimento burguês, mimado, como se Deus fosse se importar com suas contas atrasadas.

A falta de dinheiro os obriga a buscar refúgio na casa da família da Dama. No caminho eles sofrem de fome, cansaço, passam por uma ferraria onde são tidos por mendigos, até chegarem à casa dos pais da Dama, onde, devido às agruras da viagem, tornaram-se de fato mendigos. Logo vem a mente a figura do Mendigo do primeiro ato, o mendigo culto e contra o status quo, que se recusa a pagar impostos, como se sua figura indigna e desmoralizada prenunciasse o futuro próximo do Desconhecido. Chegam então na casa da família da Dama, onde moram sua mãe e seu avô. É uma família cristã e severa, que sente profunda aversão pelo escritor. A Mãe convence a filha de ler o último livro dele, apesar da proibição. Ela lê, e poucas linhas já são bastante para escandalizá-la - um exemplo das transições exageradas e sem gradação que Strindberg utilizava. O Desconhecido descobre o deslize da Dama, o que será razão suficiente para que o hipersensível autor a abandone.

Reencontramos então o protagonista em um asilo. Este é um dos momentos mais oníricos da peça. O Desconhecido não sabe se está alucinando, ao ver-se rodeado das sombras dos personagens que apareceram nas cenas anteriores, evocando figuras de seu passado. Estão de branco, em silêncio e assim permanecerão durante o decorrer da cena. Ele fica sabendo através da Abadessa que foi acolhido após ser encontrado preso de loucura e febre. Neste local ele tem a chance de se redimir, de aceitar uma salvação religiosa, mas ele a rejeita.

Retorna a casa da Mãe da Dama, onde esta não mais se encontra, tendo partido em busca dele. Antes de ir embora novamente para procurá-la, a Mãe o convence de que ele está a "caminho de Damasco", e ele no final do ato reconhece: "desejo a luz". É o primeiro sinal de esperança da trilogia, no que até então é uma sucessão de desesperos. A Dama e o Desconhecido procuram um pelo outro, deparam-se com novas "sombras" até encontrarem o Mendigo que os ajuda a se encontrarem. Começam a então a empreender o caminho de volta.

Aqui se vê que "Rumo a Damasco" é a história de uma peregrinação que dá errado. A conversão é apenas desejada, e o Desconhecido termina na mesma esquina onde tudo 
começou. É uma viagem em vão, e talvez, a resposta possa estar por detrás do pórtico da igreja gótica. O final é da peça mostra a Dama convidando-o a entrar com ela na igreja. Ele a segue, mas não sabemos se essa visita à igreja terá mais sucesso que a estadia no asilo. A desesperança que segue o protagonista onde quer que ele vá, certamente irá acompanhá-lo até dentro da igreja, e a esperança que se desprende da cena final é meramente simbólica, ou até mesmo irônica.

Quanto à misteriosa relação de personagens, a tradução inglesa de Michael Meyer, sobre qual se baseou a tradução brasileira de Elizabeth Azevedo, tomou a liberdade de explicar a presença de personagens que brotam no texto original sem terem sidos anunciados no Dramatis Personae. São, na definição do autor, "personagens menores e sombras". Deste modo, os noves personagens (Desconhecido, Dama, Mendigo, Médico, Irmã, Velho, Mãe, Abadessa, Confessor) são desdobrados em dezessete (adicionando-se aos anteriores o Dono do Café, Primeiro Convidado do Funeral, Segundo Convidado do Funeral, Terceiro Convidado do Funeral, Louco, Carregador de Hotel, Ferreiro, Mulher do Moleiro).

Discordamos desta escolha de tradução - seria melhor manter as idiossincrasias do autor, sua pontuação frenética e outras excentricidades. A função do tradutor não pode ser a de domesticar ou normalizar o autor, que, neste caso omitiu nomes de personagens não por esquecimento, e sim para frisar seu aspecto fantasmagórico, logo, não cabe corrigi-lo. Ainda em relação à escolha dos nomes dos personagens, nota-se uma alusão ao teatro medieval, com a prática de nomear os personagens não com nomes próprios, mas com abstrações humanas como Médico, Louco, Mãe, etc. Logo vêm à cabeça o mais famoso dos personagens teatrais do período medieval, o "Everyman", (1495) ou "todo homem", que ao usar alegorias no lugar indivíduos, como em "Rumo a Damasco", não pode ser confundido com ausência de dimensão dramática. (WILLIAMS, 2010). Se no primeiro caso é possível apontar os sinais do surgimento do Drama, no outro, se divisa seus limites e sua crítica.

De certo modo, o Desconhecido é uma resposta, um desenvolvimento de "Everyman" para um mundo e um teatro completamente diferentes, e, no entanto, tirando o mesmo proveito simbólico e dramático que uma alegoria pode trazer. Sobre este fato do personagem principal não ter um nome, assim se expressa Lagercrantz: 
A razão pela qual este personagem não tem um nome adequado é somente por que ele é um ponto de encontro entre diferentes figuras: como Caim, ele carrega um sinal na testa, como Jacó, ele anda mancando, e com ele estão mendigos, imperadores e criminosos. Toda humanidade foi amontoada dentro dele. Quando a contraparte do Desconhecido - a Dama - também não nomeada, indicando a representatividade deste a personagem - quando ela se compadece dele nós entendemos o motivo: ele é uma imagem atemporal do sofrimento da humanidade, e nele nós nos reconhecemos. (LAGERCRANTZ, p. 296, 1984, tradução nossa).

A peça de teatro "Rumo a Damasco" foi o anúncio de uma nova fase da dramaturgia de seu autor. Foi sua primeira peça após um período de seis anos sem escrever nenhuma obra dramática e que seria o prenúncio de uma fase abençoada em sua carreira: em ritmo febril - entre 1899 e 1903 escreveria nada menos que vinte e duas peças - tanto que até o mais ardoroso de seus defensores tem que reconhecer que nem todas são obras-primas. Com a ressalva de que as peças menores deste período ainda poderem ser consideradas acima da média. (SPRINCHORN, 1982).

Ele começou-a em fevereiro de 1898 no Hôtel Londres, em Paris. Após dias de atividade intensa, concluiu os três primeiros atos. Registrou então em seu diário, 3 de março: "Hoje eu rompi em pranto várias vezes, escrevi o final do terceiro ato". Eram lágrimas de alegria, apesar do teor trágico da peça, por ele perceber que havia reencontrado sua veia dramatúrgica, que as falas e as cenas estavam novamente brotando em sua cabeça. No dia 6 de março a peça estava completa e no dia 10 ele escreveu para seu amigo Axel Herrlin dizendo "recuperei a graça de escrever para o teatro". (LAGERCRANTZ, p. 288, 1984, tradução nossa).

No dia 8 de março ele mandou o manuscrito para seu editor, Gustaf av Geijerstam com as seguintes palavras: "Eis uma peça - não faço ideia se ela tem algum valor. Se você gostar, manda para o teatro, se achar impossível, some com ela". (MEYER, p.374 e p375, tradução nossa). Geijerstam respondeu entusiasmado e aceitou publicá-lo pagando mil coroas suecas para Strindberg, o que em valores atuais é pouco menos de dezoito mil reais. Após a publicação, a crítica se dividiu entre os que consideraram a peça "sem ação e consistência", "confusa" e os que a saudaram como sendo "uma nova força criativa, exuberante", com a ressalva feita por Georg Nordensvan, que apesar da crítica positiva escreveu: "podemos sonhar que no seu próximo trabalho, ele vá se ocupar de algo que não seja seu ego infinito?" (MEYER, 1985, p.385). Apesar do compreensível mau humor do 
jornalista, temos que agradecer a um egocêntrico genial como Strindberg, o surgimento de todo um novo ramo de dramaturgia.

A "dramaturgia do eu" pode muito bem ser acusada disso, com sua excessiva preocupação em apresentar a individualidade do poeta, com sua exposição despudorada de cada trauma, lembrança, sofrimento deste "eu", e pode então acabar se desvirtuando para uma espécie de egolatria, o equivalente dramatúrgico de uma infinita ego trip, ao abandonar uma das mais belas características da dramaturgia - a alteridade, o fiel retrato das emoções e razões dos outros. O que levou Strindberg por este caminho, paradoxalmente, era seu zelo em retratar a verdade. Quem o levou a encenar o sonho, o inconsciente foi seu fervor naturalista, convencido de que qualquer retrato do Outro está fadado à falsificação, por jamais se ter acesso completo a uma mente que não seja a do próprio autor. Ele acreditava estar utilizando a si mesmo, como cobaia para ir mais fundo do que jamais alguém poderia ter ido pelos desvãos da mente humana. Quanto a este assunto, Martin Esslin escreveu o seguinte:

Um fato significante, e um tanto paradoxal, é que o desenvolvimento do subjetivismo psicológico que se manifestou nas peças-sonhos expressionistas de Strindberg, foi o desenvolvimento direto e lógico do movimento que levou ao naturalismo. $O$ desejo de representar a realidade, toda a realidade, que em primeiro lugar conduziu a uma descrição implacavelmente verdadeira das superfícies, e então para compreensão que a realidade objetiva, superfícies, são apenas uma parte, e relativamente desimportante do mundo real. (ESSLIN, 2004, p. 353, tradução nossa). ${ }^{2}$

Nesta postura há um quê de cientificismo, de desprezo ao teatral, à máscara e a tudo que ela representa como metáfora e visão de mundo. No entanto, ao adotar essa estratégia, ele se pôs em rota de colisão com a teatralidade de seu tempo, que ainda não tinha passado pelo impacto de figuras como Stanislavski, Meyerhold, Brecht. Procurando ser científico, exato, Strindberg acabou por alargar as fronteiras do drama com elementos intangíveis da espiritualidade humana.

Quanto à falta de ação apontada por seus críticos contemporâneos, é possível notar uma influência de Maeterlinck sobre Strindberg neste aspecto, quando este evita a trama

\footnotetext{
${ }^{2}$ No original: It is a significant and somewhat paradoxical fact that the development of the psychological subjectivism that manifested itself in Strindberg's Expressionist dream plays was the direct and logical development of the movement that had led to naturalism. It is the desire to represent reality, all of reality, that at first lead to the ruthlessly truthful description of surfaces, and then on to the realization that objective reality, surfaces, are only part, and a relatively unimportant part, of the real word. (ESSLIN, 2004, p. 353).
} 
dramática convencional. Era então a última década do século XIX, momento em que estes dois, e conjunto com Chekhov, estavam em pleno processo de "desdramatizar" o drama. Para isso foram em direção ao psicológico, ao interno e estático. Eles queriam um "drama estático" - como Sprinchorn comenta nas linhas abaixo:

\begin{abstract}
Na década de 1890, mais de um escritor tentou fazer estes calmos momentos de revelação parte central do drama. Chekhov queria que suas peças fossem simples como a vida. "As pessoas jantam", ele disse (1889), "apenas jantam, e o tempo todo a sua felicidade se estabelece ou suas vidas são destroçadas". Para Maeterlinck, era um simples fato de que "o verdadeiro elemento trágico da vida somente começa no momento que as assim chamadas aventuras, tristezas e perigos desaparecem". [...] Restou a Strindberg cultivar as sementes que Maeterlinck plantara. Ele começou seu primeiro drama estático como se tivesse recebido uma deixa de Maeterlinck. (SPRINCHORN, 1982, p.76)

E mais adiante ele acrescenta sobre a desconexão entre as "estações" e a ação do protagonista: "As linhas que conectam as estações parecem ser inteiramente aleatórias. O motivo disso, é que Strindberg estava se afastando do drama convencional, no qual o protagonista exerce sua vontade e sofre suas consequências" ${ }^{3}$ (SPRINCHORN, 1982, p. 77,
\end{abstract} tradução nossa).

Se a visão da crítica oscilava entre o morno, e o medianamente empolgado, com a nova direção na carreira de seu enfant terrible, o próprio Strindberg descreveu sua peça com muito mais entusiasmo: "um gênero novo, fantástico, e luminoso como "Lucky Per", mas se passando no presente, em plena realidade" ${ }^{4}$ (OLLÉN, 1972, p. 61, tradução nossa). Ou seja, o drama de estações medieval transportado ao tempo presente, o que lhe proporcionava um realismo fantástico, anacrônico e onírico, e que the abria um leque de novas possibilidades.

A princípio nenhum teatro se interessou em produzir o novo texto. Mas após o sucesso das montagens de "Dança da Morte" e "Páscoa" (inédita em português), o Real Teatro Dramático de Estocolmo aceitou encenar "Rumo a Damasco". A estreia se deu em 19 de novembro de 1900, com direção de Emil Grandinson, com Harriet Bosse (que seria sua terceira esposa) no papel da Dama e August Palme no papel de O Desconhecido. (MEYER, $1985,410)$. Para a maior parte da crítica a peça era melhor no papel do que no palco, o

\footnotetext{
${ }^{3}$ No original: The lines connecting the stations seems to be entirely haphazard. The reason is that Strindberg was departing form the conventional drama in which the protagonist exerts his will and suffers the consequences (SPRINCHORN, 1982, p.77)

${ }^{4}$ No original: ... a new genre, fantastical and luminous like Lucky Per, but taking place in the present, and in full reality. (OLLEN, 1972, p.61)
} 
público não compreendeu bem, e que a interpretação de Palme não estava de acordo com as intenções do autor.

Strindberg participou ativamente da produção, na escolha do elenco e convenceu Grandinson a utilizar cenários estilizados e simples, para reforçar o caráter interno da trama, chegando a sugerir uma cenografia inteiramente constituída de imagens projetadas, ideia que teve que ser abandonada devido a limitações técnicas. No lugar disso, o diretor dividiu o cenário horizontalmente, criando uma área exterior e interior, ao fundo cenários de pano pintados por Carl Grabow, e muita luz de topo, criando uma desejada atmosfera de sonho. Somando-se todos esses esforços, a primeira montagem da obra, apesar de elementos tradicionais na atuação e no cenário, pode ser considerada com uma realização de vanguarda (SZALCZER, 2011, p. 55-60).

Apesar de Strindberg nunca ter sido um encenador, suas preocupações com a prática teatral são atestadas por diversos momentos em que deu sugestões a atores, diretores, cenógrafos, e, tendo iniciado sua carreira no palco grande, operístico, tradicional do Dramaten de Estocolmo, sua busca por um teatro mais interno que externo, o levou a seguir o exemplo do Kammerspiele do legendário diretor austríaco Max Reinhardt, que Strindberg visitou em 1906. Era uma sala de dança convertida em sala de espetáculo, pequena, íntima, e que possibilitava a proximidade entre atores e público. Então no ano seguinte, 1907, ele fundou o Teatro Íntimo de Estocolmo, para apenas cento e sessenta pessoas, onde finalmente suas peças naturalistas puderam ser bem realizadas e compreendidas. (BERTHOLD, 2001, p.487).

Após a estreia, a peça continuou sendo montada com frequência na Suécia, destacando-se produções como a de 1937, dirigida por Olof Molander, em que os personagens Desconhecido e Louco usavam uma máscara de Strindberg, a de 1974, dirigida pelo lendário diretor de cinema e teatro Ingmar Bergman, onde as transições sonho/realidade eram realizadas com um palco giratório, e a de 1997, dirigida por Dana Marouf, encenada dentro de um metrô, com duração de uma hora e meia, duas apresentações por dia para um público de no máximo quarenta e uma pessoas, onde o Desconhecido se transformava em O Outro, na figura de um imigrante curdo (SZALCZER, 2011, p.89). 
Na Alemanha, "Rumo a Damasco" estreou em 1914, dois anos após a morte do autor, na cidade de Berlim, com direção de Victor Barnowsky. Foi um grande sucesso, que serviu de marco para popularização da obra de Strindberg e para eclodir o expressionismo alemão. Grande parte do êxito se deveu a grande interpretação do ator Friedrich Kayssler, aclamado anos antes na versão de Max Reinhardt para o "Fausto" de Goethe, e que foi capaz de interpretar as transições entre os estados de vigília e sonho.

Uma das questões mais fascinantes desta obra é a dificuldade em estabelecer as individualidades do drama. Como estamos acostumados a sempre reconhecer nas peças pessoas discerníveis, um drama onde um personagem se espelha em outro, se parte em dois, gera a até hoje dificuldade de compreensão e fascínio. Como explica Peter Szondi, "as personagens da trilogia "Damasco" (sic) são irradiações do eu do Desconhecido, e segundo o qual a obra como um todo reside na subjetividade do seu herói". (SZONDI, p.62, 2010) e o próprio Strindberg explicaria seu método melhor que ninguém na advertência de sua peça "O Sonho":

As personagens se dividem, se duplicam, se substituem, evaporam, se condensam, se liquefazem, se intercalam. Mas uma consciência paira sobre todos - a consciência do sonhador; porque para ele não há nenhum segredo, nenhuma inconsequência, nenhum escrúpulo e nenhuma lei. Ele não julga, não rejeita, apenas relata. E por serem sonhos em sua maioria dolorosos, e raras vezes felizes, há um tom de melancolia e de compaixão por tudo que vive nas desventuras do enredo. (STRINDBERG, 1912, p.4, tradução nossa) ${ }^{5}$

Também é bom lembrar um belo sinal dos tempos, que fala por si só. Uma coincidência que marca o ano de 1900: Strindberg escreve "O Sonho" e Sigmund Freud publica o seu livro "A interpretação dos sonhos" de Freud. Comentando sobre "Rumo a Damasco", de dois anos antes, Anatol Rosenfeld também percebeu a correspondência: "sem conhecer ainda Freud, Strindberg exprimiu o inconsciente. Havia necessidade de descobri-lo; antes do criador da psicanálise ele conseguiu visualizar o próprio inconsciente". (ROSENFELD, 2009, p.240).

\footnotetext{
${ }^{5}$ No original: Personerna klyfvas, fördubblas, dubbleras, dunsta af, förtätas, flyta ut, samlas. Men ett medvetande står öfver alla, det är drömmarens; för det finns inga hemligheter, ingen inkonsekvens, inga skrupler, ingen lag. Han dömer icke, frisäger icke, endast relaterar; och såsom drömmen mest är smärtsam, mindre ofta glädtig, går en ton af vemod, och medlidande med allt lefvande genom den vinglande berättelsen. (STRINDBERG, 1912, p.4).
} 
Finalmente, é necessário reconhecer que "Rumo a Damasco" não é uma peça fácil de ser lida ou montada. Apesar de sua grande importância para história do Drama, para ser lida exige uma compreensão das tensões que o gênero dramático passava naquele período de virada do século XIX ao XX, entender o ineditismo de temas e procedimentos, a personalidade conturbada do autor, e, para ser montada requer diversos cenários, atores de grande qualidade técnica e apuro visual. Mas por outro lado, poucas peças apresentam tantos desafios intelectuais, artísticos, e tem tanto a dizer em tão pouco tempo e espaço.

\section{Referências}

ESSLIN, Martin. The Theatre of the Absurd. New York: Vintage Books, 2004.

MAGALDI, Sábato. 0 texto no teatro. São Paulo: Ed. Perspectiva, 2001.

MEYER, Michael. Strindberg: a biography. Oxford: Oxford University Press, 1985.

LAGERCRANTZ, Olof. August Strindberg. New York: Farrar, Straus and Giroux, 1984.

OLLÉN, Gunnar. August Strindberg. New York: Frederick Ungar, 1972

ROBINSON, Michael, org. The Cambridge Companion to August Strindberg. Cambridge: Cambridge University Press, 2008.

ROSENFELD, Anatol. A Arte do Teatro: Aulas de Anatol Rosenfeld (1968) / registradas por Neusa Martins. São Paulo: Publifolha, 2009.

RUGG, L. et al. The art and science of self-dramatization. In: ROBINSON, Michael (Org.). The Cambridge Companion to August Strindberg. Cambridge: University Press, 2009.

SPRINCHORN, Evert. Strindberg as dramatist. New Haven: Yale University Press, 1982.

STRINDBERG, August. Ett drömspel. Domínio Público, 1912.

STRINDBERG, August. Rumo a Damasco. Trad. Elizabeth R. Azevedo. São Paulo: Cone Sul, 1997.

STRINDBERG, August. Till Damaskus. Estocolmo: C. \& E. Gernandts, 1898.

SZALCZER, Eszter. August Strindberg. Nova lorque: Routledge, 2011.

SZONDI, Peter. Teoria do drama moderno. São Paulo: Cosac Naify, 2001.

WILLIAMS, Raymond. Drama em cena. São Paulo: Cosac Naify, 2010. 